\title{
A Non-Linear Model of Human Resource Evaluation
}

\author{
Xiaohong Liu \\ College of management, Southwest University for Nationalities, Chengdu 610041, P.R. China
}

\begin{abstract}
This paper presents a non-linear model for synthesizing the result of human resource evaluation. According to the degree of influenced by position of human resource's basic diathesis, evaluation factors are divided into two parts in this model, i.e. dominance index and recessive index. When the result of dominance index confirmed, whether human resource is competent for the position or not that is decided by the recessive index, and the relation of related competence to recessive index is non-linear.
\end{abstract}

Keywords:Human resource, Evaluation, Competence, Uncertainty

\section{Introduction}

Since Peter F. Drucker in 1954 in the Practice of Management (Drucker, 1954) first put forward the concept of human resource, great progress has been made in the theory of human resource management, meanwhile, it plays an important role in guiding the practice of management. Since 1990s, human resource has been considered as a kind of strategic contributors in an enterprise, as result, the though and a series of methods of the strategic management of human resource have been formed. In some degree, the management of human resource becomes the strategic management of human resource. How to treat and determine the value of human resource becomes an important researching content in the strategic management of human resource (Baron, 2003; Dennis, 2002; Grabot, 2000; Gunderson, 2001; Hagan, 1996; Jeong, 2002; Kaufman, 2001; Pinker, 2003; Remus, 2002; Wang, 2003).

The origin of competence can be traced back the later 1960s, the idea of competence was put forward by David McClelland who is a psychologist at Harvard University and his team through a plenty of researches. The traditional theoretical model of personnel assessment cannot foresee performance and personal success, and more, it lacks fairness. They discovered the important factors that affect individual's performance are such as achievement motivation, person occasion understanding, and group team influence and so on. According to McClelland, it is necessary to give up the traditional assessment technique and method, and the researcher should seek a kind of variable that can cause to succeed, and at the same time do not have prejudice, then, to develop a kind of objective method that can describe the identification. Under such background, McClelland has developed the concept of competence as a centre of personnel assessment; its purpose is to face future, performance, objective and operability. In 1973, McClelland published the article of Testing for competence rather than for intelligence (McClelland, 1973) that provided the birth foundation of the competence theory.

A majority of traditional personnel evaluation and its measurement model is the linear model that is composed mainly with the basic quality or intelligence of person, and in other words, the method of calculating the result of evaluation is summing value with power weight for the score of index. Because of the uncertainty of correlation between achievement of job and basic quality or intelligence of person, it's obvious that the high grade of evaluation of quality or intelligence of human resource can not definitely meet the specific working post and ambient conditions of organization. It's not the most important for organization of traditional personnel evaluation. Actually, what organization need of human resource management (HRM) is that satisfy the needs organization's tasks and individual's interesting.

\section{Basic hypothesis}

In the process of studying competence evaluation, We divided the evaluation index of basically quality of human resource into two types, i.e. measurable index and recessive index, and the measurable index's is composed by knowledge, skill and body of human resource, which is the three essential factors of the concept of human resource, the recessive index is composed by interest and psychology of human resource (Liu etc., 2005).

For establishing the evaluation model of human resource relatively reasonably, We put forward the following basic hypothesis.

(1) There are two type factors affect competence: according to the viewpoint of optimization combination of the essence of competence that is 
through the human resource's basic conditions such as psychology, interest, knowledge, ability, body and so on under specific working post and ambient conditions to obtain high performance, it can be generalized influencing competence two basic factors that are internal environment of person (use Se to show, it includes personal psychology, interest, knowledge, ability and body) and external environment of person (use Oe to show, it includes enterprise sense and human relations). The internal environment of person is the foundation that forms the competent force of person, and the interact result of the factors of internal environment of person and the factors of external environment determines the difference in degree of competence.

(2) Measurable index and recessive index: the evaluation index of basic quality of human resource is divided into the measurable index and recessive index according to the difference of its degree that influenced by the external environment. The measurable index that is influenced less by the external environment includes knowledge, skill and body of human resource. The recessive index that is influenced greatly by the external environment includes interest and psychology of human resource.

(3) The process of producing the high performance: to insure human resource qualified for the post, it's necessary that the result of evaluation of measurable index meet the basic requisition. When the result of measurable index is a invariant, the competence of human resource is determined mainly by the result of recessive index. If the result of recessive index tends to a very low value, i.e. human resource do not like this working post, the degree of satisfaction of the human resource is very low, and its competence will be low level also. In the same way, if the result of recessive index tends to a very high value, that is human resource like this working post very much, and its competence will be a high level. The relation between the recessive index increasing and the high performance is a kind of nonlinear monotonous.

\section{An index and its value of evaluation of human resource}

The index and its method of evaluation play an important role in the system of evaluation of human resource. Basically, there are different explanation of index and its value of evaluation for different types organization. We present a general structure of the index and a method of value for evaluation of human resource in this section.

\subsection{An index of evaluation of human resource}

According to the thought of competence evaluation of human resource, we build an index of evaluation of human resource that is shown as Table 1. It's obvious that a relatively reasonable index of evaluation of human resource plays an important role in the system of evaluation of human resource.

\begin{tabular}{|c|c|c|}
\hline Factor type & Father indexes & Subclass indexes \\
\hline \multirow{10}{*}{$\begin{array}{l}\text { Internal } \\
\text { environment } \\
\text { (Se) }\end{array}$} & \multirow{2}{*}{$\begin{array}{l}\text { Psychological } \\
\text { (Se1) }\end{array}$} & Nature feature \\
\hline & & Risk attitude \\
\hline & \multirow{2}{*}{$\begin{array}{l}\text { Interest } \\
(\mathrm{Se} 2)\end{array}$} & Interest kind \\
\hline & & Interest strength \\
\hline & \multirow{2}{*}{$\begin{array}{l}\text { Knowledge } \\
\text { (Se3) }\end{array}$} & General knowledge \\
\hline & & $\begin{array}{l}\text { Professional } \\
\text { knowledge }\end{array}$ \\
\hline & \multirow{2}{*}{$\begin{array}{l}\text { Ability } \\
\text { (Se4) }\end{array}$} & General ability \\
\hline & & Special ability \\
\hline & \multirow{2}{*}{$\begin{array}{l}\text { Body } \\
\text { (Se5) }\end{array}$} & Basic condition \\
\hline & & Movement reaction \\
\hline
\end{tabular}

Table 1: An index of evaluation of human resource.

The explanation of subclass indexes of Table 1 is as followings.

Nature feature. For the nature of different type can use Carter special character theoretical measure

Risk attitude. Risk attitude is affected by factor, and it has stability in certain period.

Interest kind. Person has various types interest, and we can get its result through testing

Interest strength. It is different in the strength of person' interest and we can get its result through testing.

General knowledge. General knowledge has universal meaning in working, and we can get its result through testing.

Professional knowledge. Professional knowledge that is demanded in special working, and we can get its result through checking certificates or testing

General ability. It includes person's occasion ability, learning ability and meet ability, and its result is difficult to be gotten.

Special ability. It is special ability of different fields that are difficult to be gotten.

Basic condition. It is healthy condition that can be gotten through testing.

Movement reaction. It is the reaction speed for outside that can be gotten through observing.

\subsection{A method of value of evaluation of human resource}


There are many methods of value of evaluation of human resource, and relatively common used methods such as figure, percent, natural number, linguistic value and so on. There exists an approximate relation among different method of value. For fuzzy comprehensive evaluation, set the comments sets $(V)$ as very satisfactory $\left(k_{1}\right)$, satisfactory $\left(k_{2}\right)$, general $\left(k_{3}\right)$, unsatisfactory $\left(k_{4}\right)$, and very unsatisfactory $\left(k_{5}\right)$, and $V=k_{1} \cup k_{2} \cup \ldots \cup k_{5}$.

The relation of comments sets of different methods based on the degree of satisfaction is shown as Table2, and the symbol of $\mathrm{M}$ and $\mathrm{D}$ denotes the method and degree of satisfaction relatively, and the explanation of other symbols is as followings.

M1 denotes the method of percent.

M2 denotes the method of close interval $[0,1]$

M3 denote the method of linguistic value

M4 denote the method of natural number.

\begin{tabular}{|l|l|l|l|l|l|}
\hline $\begin{array}{l}\text { D } \\
\text { M }\end{array}$ & \multicolumn{1}{|c|}{$k_{1}$} & $k_{2}$ & \multicolumn{1}{|c|}{$k_{3}$} & $k_{4}$ & \multicolumn{1}{|c|}{$k_{5}$} \\
\hline M1 & {$[90,100]$} & {$[75,90]$} & {$[60,75]$} & {$[40,60]$} & {$[0,40]$} \\
\hline M2 & {$[0.9,1]$} & {$[0.75,0.9]$} & $[0.6,0.75]]$ & {$[0.4,0.6]$} & {$[0,0.4]$} \\
\hline M3 & $\begin{array}{l}\text { Very } \\
\text { good }\end{array}$ & Good & General & Bad & $\begin{array}{l}\text { Very } \\
\text { bad }\end{array}$ \\
\hline M4 & 5 & 4 & 3 & 2 & 1 \\
\hline
\end{tabular}

Table 2: An approximate relation among different method of value based on satisfaction degree.

In theoretical view, the difference based on the method of percent and close interval $[0,1]$ is clearer than the method based on linguistic value and natural number, and the approximate relation between the two methods can be considered as completely consistent. However, in actual application, the result of evaluation based on the relatively reasonable linguistics value and natural number is more useful than the result based on the percent and close interval $[0,1]$. The methods of linguistics value and natural number are widely used in the course of evaluation of human resource because they are close to the thought of mankind with uncomplicated.

\section{A non-linear model}

In the process of traditional personnel measurement and evaluation, the basic conditions of human resource, such as body, interest, knowledge, ability and the psychology of person are taken into independence of indexes each other, and the result finally general adopting $t$ the method of linear with summing value. According to the basic hypothesis, we present a non- linear of evaluation of human resource. The comparison between traditional evaluation model and non-linear model is shown as Fig.1

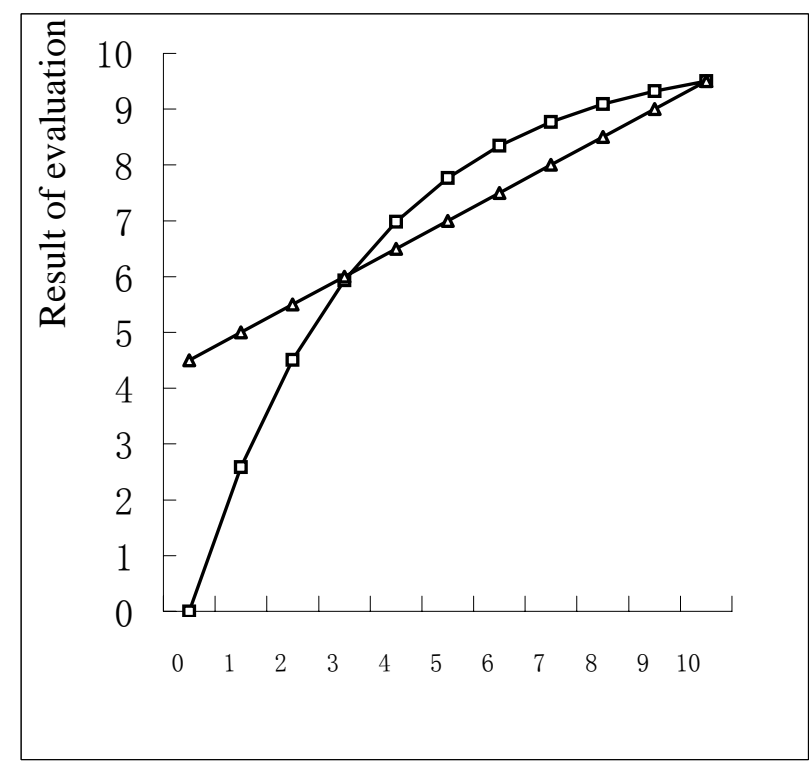

Fig.1: The comparison between the traditional evaluation and competence evaluation.

In a traditional appraisement model:

$$
Q_{i}=(1-\lambda) \sum_{j=1}^{m} r_{i j} a_{i j}+\lambda \sum_{k=1}^{n} w_{i k} u_{i k}
$$

In (1), $Q_{i}$ expresses the membership degree of the appraising result subordinating to the $i$ appraise comment, $a_{i j}$ and $u_{i k}$ are the degrees that the $j$ dominance index and the $k$ recessive index subordinating to the $i$ appraisement comment respectively; $r_{i j}, w_{j k}, \lambda$ and $(1-\lambda)$ are the weights of the $j$ dominance index, the $k$ recessive index, all recessive indices and all dominance indices respectively, and $0 \leq \lambda \leq 1, \sum_{j=1}^{m} r_{i j}=1, \sum_{k=1}^{n} w_{i k}=1$.

According to the biggest membership degree principle, the appraise result in traditional appraisement model is finally determined as:

$$
Q_{k}=\max \left\{Q_{1}, Q_{2}, \ldots Q_{r}\right\}
$$

According to (2), the appraisement result belongs to the $k^{\text {th }}$ appraisement comment relatively.

There is, in a competence appraisement, an appraisement result synthetic general model that is constructed as (3):

$$
P_{i}=C_{s}\left(1-b^{t}\right)
$$




$$
b=\left\{\frac{1-\frac{1}{\left(C_{s}\right)^{2}} \sum_{j=1}^{m}\left(r_{i j} a_{i j}\right) \sum_{k=1}^{n}\left(w_{i k} u_{i k}\right)}{\left[1+\frac{1}{C_{s}} \sum_{j=1}^{m}\left(r_{i j} a_{i j}\right)\right]^{s}}\right\}
$$

For technological post or operational post,

$$
t=\sum_{k=1}^{m} w_{k} u_{k}
$$

For decision post or management post,

$$
t=\frac{1}{\left(C_{s}\right)^{n}} \prod_{k=1}^{n} u_{k}
$$

In (4), $P_{i}$ expresses the degree that the appraisement result is subordinate to the $i^{\text {th }}$ appraisement comment; $a_{i j}$ and $u_{i k}$ are the degrees that the $j^{\text {th }}$ dominance index and the $k^{\text {th }}$ recessive index is subordinate to the $i^{\text {th }}$ appraisement comment respectively. Sort $u_{i k}$ descendent by the satisfactory degree for recessive indices, i.e., the satisfactory degree of $u_{(i-1) k}$ is better than that of $u_{i k}$, and stipulate $p_{i k}=\max \left\{u_{1 k}, u_{2 k}, \ldots, u_{i k}\right\} ; r_{i j}$ is the weight of the $j^{\text {th }}$ dominance index, and $\sum_{j=1}^{m} r_{i j}=1 ; n$ is the relevant coefficient of appraising working post, $n \geq 1$, and the higher the coordinate requirement of the working post, the bigger $S$. For the case of decision, management, technical and schoolwork post, $S$ can take 5, 3, 2, and 1, respectively.

\section{One example}

Set there are three candidates for one decision post, and the value of evaluation's comments is 1,2,3,4and 5 ,which denotes the degree of satisfaction from low to high, and the power weight of each index is sameness, i.e. $r_{j}=\frac{1}{6}, w_{k}=\frac{1}{4}$ and $\lambda=\frac{1}{2}$.

According to the Table1, we get the result of evaluation for three candidates that is shown as Table 3.

\begin{tabular}{|l|llllllllll|}
\hline Candidate & $\mathrm{S}_{1}$ & $\mathrm{~S}_{2}$ & $\mathrm{~S}_{3}$ & $\mathrm{~S}_{4}$ & $\mathrm{~S}_{5}$ & $\mathrm{~S}_{6}$ & $\mathrm{~S}_{7}$ & $\mathrm{~S}_{8}$ & $\mathrm{~S}_{9}$ & $\mathrm{~S}_{10}$ \\
\hline 1 & 5 & 3 & 4 & 4 & 5 & 5 & 5 & 3 & 5 & 4 \\
2 & 5 & 5 & 4 & 4 & 5 & 4 & 3 & 4 & 4 & 4 \\
3 & 5 & 5 & 4 & 5 & 4 & 4 & 4 & 4 & 3 & 3 \\
\hline
\end{tabular}

Table 3: The result of evaluation for three candidates.

According to the formula of traditional model, we can calculate the result, $Q_{1}=4.25, Q_{2}=4.25$,
$Q_{3}=4.21$, and $Q_{1}=Q_{2} \succ Q_{3}$. According to the principle of priority order of choice from the high score to low, we should choose the candidate 1 or 2 .

Using the model presented by this paper, set the parameter of post $S=5, t$ is calculated by the fomula (6) , the result of calculation of the three candidates good for the post is shown as Table 4.

\begin{tabular}{|l|l|l|l|}
\hline \multicolumn{1}{r|}{ Candidate } & 1 & 2 & 3 \\
\hline$t$ & 0.384 & 0.640 & 0.800 \\
\hline$b$ & 0.0112 & 0.0118 & 0.0200 \\
\hline$P$ & 4.11 & 4.71 & 4.78 \\
\hline
\end{tabular}

Table 4: The result of calculation of the three candidates.

According to the result of competence evaluation, have $P_{3} \succ P_{2} \succ P_{1}$, that is the candidate of 3 is priority to 2 and 1 , which illustrate the factors of psychology and interest affect the result of evaluation greatly. In fact, the factors of psychology and interest play very important role for the post of making decision and management, therefore, if we adopt the traditional evaluation model, it's very possible that the candidate who gets a high score will not be up to the post.

\section{Conclusions}

There are many factors that affect the rationality of evaluation and the validity of application of result. Actually, a major of factors of the evaluation of human resource belongs to uncertainty. To be good for the post, this paper presented a non-linear model of evaluation of human resource, and this model can be used to explain the validities and improve the relative objectivity of evaluation of human resource, at the same time, this model is helpful to raise the scientific ness of the management of human resource, to offer theoretical algorithm for establishing the management expert of human resource.

\section{Acknowledgment}

We gratefully acknowledge the support of Doctor Innovation Foundation of SWUN (07SBS003) and National Natural Science Foundation of China (Grant No.60474022)

\section{References}

[1] R. A. Baron, Human resource management and entrepreneurship: some reciprocal benefits of closer links, Human Resource Management Review, 13(2): 253-256, 2003. 
[2] R. E. Boyatzis, The competent manager, a model for effective performance, McBer and Company, John Wiley and Sons, Inc. 1982.

[3] B. A. Dennis, A.L. Debra and M. Charlie, Using job satisfaction and pride as internal-marketing tools, The Cornell Hotel and Restaurant Administration Quarterly, 43(2): 87-96,2002.

[4] P. F. Drucker, The Practice of Management, New York, Harper \& Brothers, pp.264, 1954.

[5] D. C. McClelland, Testing for competence rather than for intelligence, American Psychologist, 28(1): 1-14,1973.

[6] E. H. Schein, Career Dynamics: Matching Individual and Organizational Needs, AddisonWesley publishing company,1978.

[7] X.H. Liu, D. Ruan and Y. Xu, A study of enterprise human resource competence appraisement, Journal of enterprise information management, 18(3): 289-315, 2005. 